\title{
Discovering novel mechanisms of taxane resistance in human breast cancer by whole-exome sequencing
}

\author{
YUMI WANIFUCHI-ENDO ${ }^{1}$, NAOTO KONDO ${ }^{1}$, YU DONG $^{1}$, TAKASHI FUJTA ${ }^{1}$, \\ TOMOKO ASANO $^{1}$, TOMOKA HISADA ${ }^{1}$, YASUAKI UEMOTO ${ }^{1}$, SAYAKA NISHIKAWA ${ }^{1}$, \\ YUSUKE KATAGIRI $^{1}$, AKIKO KATO ${ }^{1}$, MITSUO TERADA ${ }^{1}$, HIROSHI SUGIURA ${ }^{2}$, \\ KATSUHIRO OKUDA $^{3}$, HIROYUKI KATO ${ }^{4}$, SATORU TAKAHASHI ${ }^{4}$ and TATSUYA TOYAMA ${ }^{1}$ \\ ${ }^{1}$ Department of Breast Surgery, ${ }^{2}$ Education and Research Center for Advanced Medicine, \\ Departments of ${ }^{3}$ Oncology, Immunology and Surgery, and ${ }^{4}$ Experimental Pathology and Tumor Biology, \\ Nagoya City University Graduate School of Medical Sciences, Nagoya 467-8601, Japan
}

Received April 8, 2021; Accepted November 12, 2021

DOI: $10.3892 / 01.2021 .13178$

\begin{abstract}
Taxanes are important drugs used in the treatment of breast cancer; however, some cancer types are taxane-resistant. The aim of the present study was to investigate the underlying mechanisms of taxane resistance using whole-exome sequencing (WES). Six patients with breast cancer whose tumors responded well to anthracycline treatment but grew rapidly during neoadjuvant taxane-based chemotherapy, were included in the present study. WES of samples from these patients was carried out to identify somatic mutations of candidate genes thought to affect taxane resistance, and the candidate proteins were structurally modeled. The mRNA and protein expression levels of these candidate genes in other breast cancers treated with taxanes were also examined. Nine variants common to all six patients were identified and two of these [R552P in V-type proton ATPase catalytic subunit A (ATP6V1A) and T114P in apolipoprotein B MRNA editing enzyme catalytic subunit $3 \mathrm{~F}(A P O B E C 3 F)]$ were selected.
\end{abstract}

Correspondence to: Dr Naoto Kondo, Department of Breast Surgery, Nagoya City University Graduate School of Medical Sciences, 1 Kawasumi, Mizuho-cho, Mizuho-ku, Nagoya 467-8601, Japan

E-mail: nkondo@med.nagoya-cu.ac.jp

Abbreviations: WES, whole-exome sequencing; ATP6V1A, V-type proton ATPase catalytic subunit A; APOBEC3F, apolipoprotein B mRNA editing enzyme catalytic subunit 3F; DFS, disease-free survival; OS, overall survival; NAC, neoadjuvant chemotherapy; ABC, ATP-binding cassette; NGS, next-generation sequencing; PDB, protein data bank; IHC, immunohistochemistry; ER $\alpha$, estrogen receptor $\alpha$; PgR, progesterone receptor; HER2, human epidermal growth factor receptor 2; VAF, variant allele frequency; V-ATPase, vacuolar $\mathrm{H}^{+}$-ATPase; ROC, receiver operating characteristic; AUC, area under the curve; HCC, hepatocellular carcinoma

Key words: breast cancer, taxane resistance, ATP6V1A, APOBEC3F
The results also showed that, protein-structure visualization suggested that these mutations may cause structural changes. The Kaplan-Meier analyses revealed that higher APT6V1A and $A P O B E C 3 F$ expression levels were significantly associated with poorer disease-free survival (DFS) and overall survival. Moreover, multivariate analysis identified high ATP6V1A mRNA expression as an independent risk factor for poor DFS. Two specific mutations that might affect taxane resistance were identified. Thus, these results suggest that breast cancer patients receiving taxanes who have high ATP6V1A or $A P O B E C 3 F$ expression levels may have shorter survival.

\section{Introduction}

Neoadjuvant chemotherapy (NAC) is the standard of care for patients with locally advanced breast cancer (1). However, breast cancer continues to progress during taxane-based NAC in $3-6 \%$ of patients $(2,3)$. These patients have poorer survival than patients whose breast cancer responds well to NAC (2).

Taxanes are important breast cancer drugs used worldwide for both adjuvant therapy and treatment after recurrence. They arrest proliferation and cause the death of cancer cells (4). The main target of taxanes is $\beta$-tubulin. After binding to $\beta$-tubulin, taxanes stabilize the microtubules and disrupt their dynamics, thus interrupting microtubule-associated functions in mitotic cells (4). Mechanisms of taxane resistance have been widely studied. One mechanism involves microtubule alterations, whereby mutations of the TUBAIA and TUBB genes and alterations in microtubule-associated proteins affect taxane binding and microtubule dynamics (5). Another mechanism involves ATP-binding cassette (ABC) transporters. ABC transporters work as drug efflux pumps that mediate the transmembrane transport of intracellular substrates, such as taxanes (6). Overexpression of the ABC transporter, ABCB1, and upregulation of $\mathrm{ABC}$ transporters have been reported to affect taxane resistance (7). Although many other mechanisms (e.g., DNA repair and reactive oxygen species metabolism) have been reported (4), the mechanism of taxane resistance remains unclear. 
The development of next-generation sequencing (NGS) has allowed extensive genomic information on individual tumors to be obtained in an extremely short period of time. Specific mutations identified by NGS may affect therapeutic efficacy and induce resistance to some treatments (8). For example, NGS analysis reportedly indicated that PIK3CA mutations reduced sensitivity to anthracycline-taxane-based NAC (9).

The present study included six patients with breast cancer whose tumors responded well to anthracycline treatment but showed rapid growth during taxane treatment with NAC. Therefore, the hypothesis was that these six tumors may express common mutations involved in taxane resistance. In the present study, the novel mechanisms of taxane resistance in breast cancer using NGS were examined.

\section{Materials and methods}

Patients and breast cancer tissues. A total of 1,707 patients with primary breast cancer were treated at the Department of Breast Surgery, Nagoya City University Hospital, between January 2001 and December 2012, including 98 patients with primary invasive breast cancer who were treated with anthracycline-taxane-based NAC. Of these 98 patients, six had tumors that initially responded well to anthracycline treatment but showed rapid growth during taxane treatment. Breast cancer tissue samples from these six patients were collected and analyzed by WES (Fig. 1). The inclusion criterion was patients with primary breast cancer who had undergone surgical treatment and the exclusion criterion was stage IV breast cancer.

Of the 1,707 patients, 119 patients used taxanes as adjuvant therapy before and after surgery. Sanger sequencing and mRNA expression measurements were performed using the 119 samples. The measured genes were V-type proton ATPase catalytic subunit A (ATP6V1A) and apolipoprotein B mRNA editing enzyme catalytic subunit $3 \mathrm{~F}$ (APOBEC $3 F)$. Samples of breast cancer tissues from 102 of these 119 patients were also included to evaluate ATP6V1A and APOBEC3F protein expression levels. All 1,707 patients underwent surgical treatment. Concerning treatment, the 119 patients who underwent taxane treatment also received 12 cycles of paclitaxel $\left(80 \mathrm{mg} / \mathrm{m}^{2}\right.$ once weekly) or four cycles of docetaxel $\left(75 \mathrm{mg} / \mathrm{m}^{2}\right.$ once every 3 weeks) for adjuvant therapy. Patients with hormone receptor-positive breast cancer $(n=99)$ received appropriate endocrine therapy (Fig. 1). Computed tomography scans were performed to determine the tumor diameter and efficacy of each NAC regimen.

The study protocol was approved by the Institutional Review Board of Nagoya City University (approval no. 70-00-0172; Nagoya, Japan) and conformed to the guidelines of the 1996 Declaration of Helsinki. Written informed consent for the use of resected tumor tissues was provided by all patients before treatment.

DNA extraction and WES. DNA was extracted from approximately $500 \mathrm{mg}$ of frozen breast cancer tissue using a salt precipitation method, as described previously (10). DNA samples were enriched for WES using a SureSelect XT Human All Exon v.5 Kit (Agilent Technologies). Sequencing was performed on an Illumina HiSeq system (Illumina) with 100-bp paired-end runs, following the manufacture's protocols. The primer sequences used were: Read1, ACACTCTTTCCC TACACGACGCTCTTCCGATCT; Read2, GTGACTGGA GTTCAGACGTGTGCTCTTCCGATCT. Image analysis and base calling were performed using Genome Analyzer Pipeline version 1.5 (SeqNova $^{\mathrm{TM}}$ CSmapping, Hokkaido System Science Co., Ltd.) with the default parameters. Sequence reads were aligned to human genome assembly hg19 (GRCh37) and variants were identified using DNAnexus software (Palo Alto) using default parameters.

Structural modeling of ATP6VIA and APOBEC3F proteins. ATP6V1A protein conformations from wild-type and mutant genes were simulated using PDFAMS software (In-Silico Sciences Inc.) with reference to the protein data bank (PDB) ID 5BN4_A protein. ATP6V1A octamer conformations were simulated with reference to PDB ID 3VR6_ABCDEFGH protein. The APOBEC3F N-terminal and C-terminal conformations from wild-type and mutant genes were simulated with reference to PDB ID 5K83_A and ID 5K83_D proteins, respectively. Each terminal model was connected to construct the complete predicted model of APOBEC3F.

Polymerase chain reaction (PCR) and Sanger sequencing. DNA was extracted from the breast cancer tissues of 119 taxane-treated breast cancer patients. PCR was performed once using $1 \mu \mathrm{g}$ DNA from each sample. The PCR reactions were performed using an LA-Taq Kit (Takara Bio Inc.) in a $50-\mu 1$ reaction volume, as described previously (10). The primer sequences used were: ATP6V1A: (forward) 5'-ACT CTGGTTAAGTAGTTGGTC-3', (reverse) 5'-ATCGTTTGA ACCCAGGAGGCAGAG-3'; APOBEC3F: (forward) 5'-AGA AATGTGCTTCCTCTCTTGGTTC-3', (reverse) 5'-ATCTTT CATGCTGTTCCTCCCGCTC-3'. The cycling conditions were as follows: initial denaturation at $94^{\circ} \mathrm{C}$ for $10 \mathrm{~min}$, and 40 cycles of $94^{\circ} \mathrm{C}$ for $30 \mathrm{sec}, 53^{\circ} \mathrm{C}$ for $30 \mathrm{sec}$ and $72^{\circ} \mathrm{C}$ for $30 \mathrm{sec}$ for the melting, annealing, and elongation phases of the reaction, respectively. The products were purified using a Qiagen PCR purification kit (Qiagen, Inc.). Mutations in the two genes were analyzed by direct sequencing using an ABI Prism 3100 analyzer (Thermo Fisher Scientific, Inc.). The mutations were then analyzed by BLAST, and chromatograms were analyzed by manual review in both forward and reverse sequences (10).

RNA extraction and reverse transcription quantitative polymerase chain reaction $(R T-q P C R)$. Total RNA was extracted from frozen breast cancer tissue sections using an RNeasy Mini Kit (Qiagen) according to the manufacturer's protocol, as described previously. RT was performed using a High-Capacity cDNA Reverse Transcription Kit (Thermo Fisher Scientific, Inc.) according to the manufacturer's protocol (11). The High-Capacity cDNA Reverse Transcription Kit included RT Buffer, RT Random Primers, dNTP Mix and MultiScribe Reverse Transcriptase. TaqMan Gene Expression assays (Thermo Fisher Scientific, Inc.) were used to measure mRNA expression levels of ATP6V1A, APOBEC $3 F$, and the housekeeping gene $A C T B$. RT-qPCR was performed using a 7500 Fast Real-Time PCR System (Thermo Fisher Scientific, Inc.). Samples were amplified independently in duplicate. 


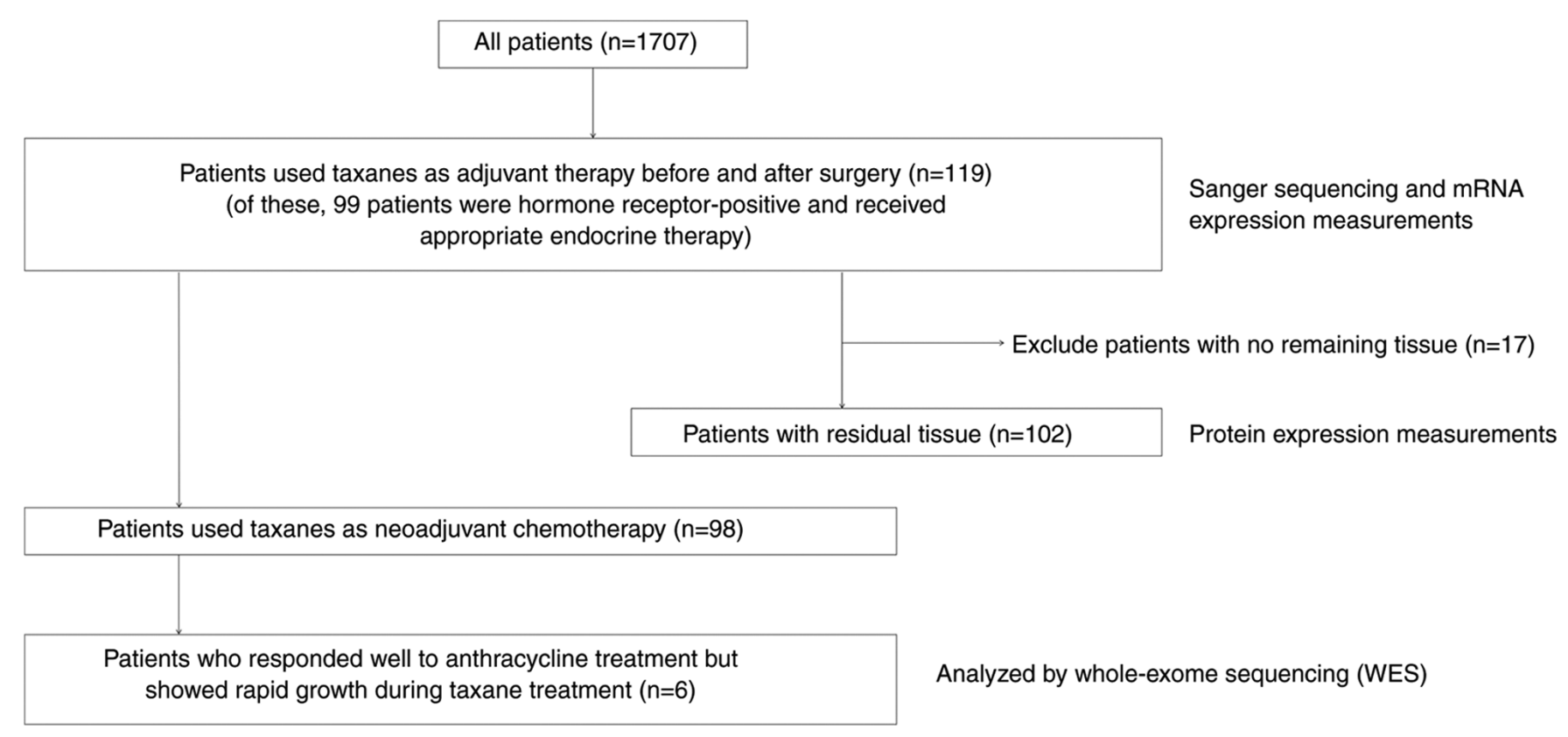

Figure 1. CONSORT statement flow diagram.

The results were converted into relative concentrations using an in-run standard curve, and then normalized to the mean values of $A C T B$ to account for variations in the amount of input cDNA (11). The assay numbers were Hs01097169_m1 for ATP6V1A, Hs01665324_m1 for APOBEC3F, and 4333762T for $A C T B$ (Thermo Fisher Scientific, Inc.).

Immunohistochemistry (IHC). Tissues were fixed by immersion in $10 \%$ neutral buffered formalin at room temperature for 24-48 $\mathrm{h}$ and then embedded in paraffin to prepare sections. A section $(4 \mu \mathrm{m})$ from each paraffin-embedded specimen was first stained with hematoxylin and eosin to ascertain whether it included enough invasive ductal carcinoma cells and if the fixation quality was adequate for IHC analysis, as described previously (11). Serial sections were then prepared from suitable tissue blocks and float-mounted on adhesive-coated glass slides for the staining of estrogen receptor $\alpha(E R \alpha)$, progesterone receptor $(\mathrm{PgR})$, and human epidermal growth factor receptor 2 (HER2) using the following primary antibodies: mouse monoclonal anti-human antibodies against $\mathrm{ER} \alpha$ (1:100, 1D5; Dako), PgR (1:100, PgR636; Dako), and rabbit anti-human c-erbB2 oncoprotein antibody (1:200; Dako) to stain for HER2, as well as rabbit polyclonal anti-human ATP6V1A antibody (1:100, ab103445; Abcam) and rabbit polyclonal anti-human APOBEC3D+APOBEC3F antibody (1:50, ab74205; Abcam). The Dako EnVision system (Dako) was used to detect ER $\alpha, \operatorname{PgR}$, and HER2. Expression levels of ER $\alpha$ and $\mathrm{PgR}$ were scored by assigning proportion and intensity scores, according to Allred's procedure (12). HER2 immunostaining was evaluated using the HercepTest (Dako) and fluorescence in situ hybridization (13). For the IHC analysis of ATP6V1A and APOBEC3F, tissue microarrays were prepared on $2 \mathrm{~mm}$ diameter slides after confirming whether an appropriate number of invasive ductal carcinoma cells were present and whether the fixation quality was suitable for IHC analysis. The ATP6V1A and APOBEC3F protein expression levels were evaluated according to the cytoplasmic H-score, which was calculated by assessing the entire slide using the Aperio Image Scope system (Leica Biosystems). Cytoplasmic staining intensity $(0,1+, 2+$, or $3+)$ was determined for each cancer cell. An H-score was assigned using the formula $[1 \mathrm{x}(\%$ cells $1+)+2 \mathrm{x}(\%$ cells $2+)+3 \mathrm{x}(\%$ cells $3+)](14,15)$.

Prediction methods. The damaging effects of mutations were predicted using the web-based algorithms PolyPhen2 v2.2.2 (http://genetics.bwh.harvard.edu/pph2/), PROVEAN v1.1 (http://provean.jcvi.org/index.php), SIFT v5.0.3 (http://sift. bii.a-star.edu.sg/), FATHMM v2.3 (http://fathmm.biocompute. org.uk/) and Mutation Taster (https://www.mutationtaster. org/). Polyphen2, PROVEAN and SIFT classification tools were used to extract mutations that are most likely to affect protein function. Two additional online tools (FATHMM and Mutation Taster) were used to study the effect on the protein function. FATHMM and Mutation Taster were selected because they are widely used and score the pathological effects of mutations that have been extracted on the basis of the protein function. The relationship between the genes was examined using GeneMANIA v3.6.0 (https://genemania.org/).

Statistical analyses. mRNA expression levels and IHC results were analyzed by researchers blinded to the clinical data. Statistical calculations were performed using JMP 13 software (SAS Institute, Inc.). Data are presented as mean \pm standard deviation. Receiver operating characteristic (ROC) analyses were used to determine the optimal cut-off level for mRNA and protein expressions, which were assessed using Youden's index. Disease-free survival (DFS) was censored at the date of last follow-up if patients were still relapse-free and alive, and overall survival (OS) was censored at the time when patients were alive. DFS and OS were evaluated using the Kaplan-Meier method and differences between survival curves were assessed with the log-rank test. Cox's proportional hazards model was 
Table I. Characteristics of breast cancer tumors intrinsically resistant to taxanes $(n=6)$.

\begin{tabular}{|c|c|c|c|c|c|c|c|c|c|}
\hline Patients & $\begin{array}{c}\text { Age } \\
\text { (years) }\end{array}$ & Histology & $\begin{array}{l}\text { Nuclear } \\
\text { grade }\end{array}$ & $\begin{array}{l}\text { ER (Allred } \\
\text { score) }\end{array}$ & $\begin{array}{l}\text { PgR (Allred } \\
\text { score) }\end{array}$ & $\begin{array}{c}\text { HER2 } \\
\text { IHC }\end{array}$ & $\begin{array}{l}\text { HER2 } \\
\text { FISH }\end{array}$ & $\begin{array}{l}\text { Blood } \\
\text { sample }\end{array}$ & $\begin{array}{l}\text { Year of } \\
\text { surgery }\end{array}$ \\
\hline 1 & 31 & Invasive ductal carcinoma & 2 & 2 & 0 & $1+$ & & NA & 2006 \\
\hline 2 & 36 & Invasive ductal carcinoma & 3 & 0 & 0 & 0 & & $(+)$ & 2008 \\
\hline 3 & 50 & Invasive ductal carcinoma & 3 & 5 & 0 & 0 & & $(+)$ & 2009 \\
\hline 4 & 61 & Invasive ductal carcinoma & 3 & 4 & 0 & $1+$ & & NA & 2010 \\
\hline 5 & 52 & Invasive ductal carcinoma & 1 & 3 & 0 & $2+$ & Negative & $(+)$ & 2012 \\
\hline 6 & 38 & Invasive ductal carcinoma & 3 & 2 & 0 & $1+$ & & NA & 2012 \\
\hline
\end{tabular}

ER, estrogen receptor; FISH, fluorescence in situ hybridization; HER2, human epidermal growth factor receptor 2; IHC, immunohistochemistry; NA, not available; PgR, progesterone receptor.

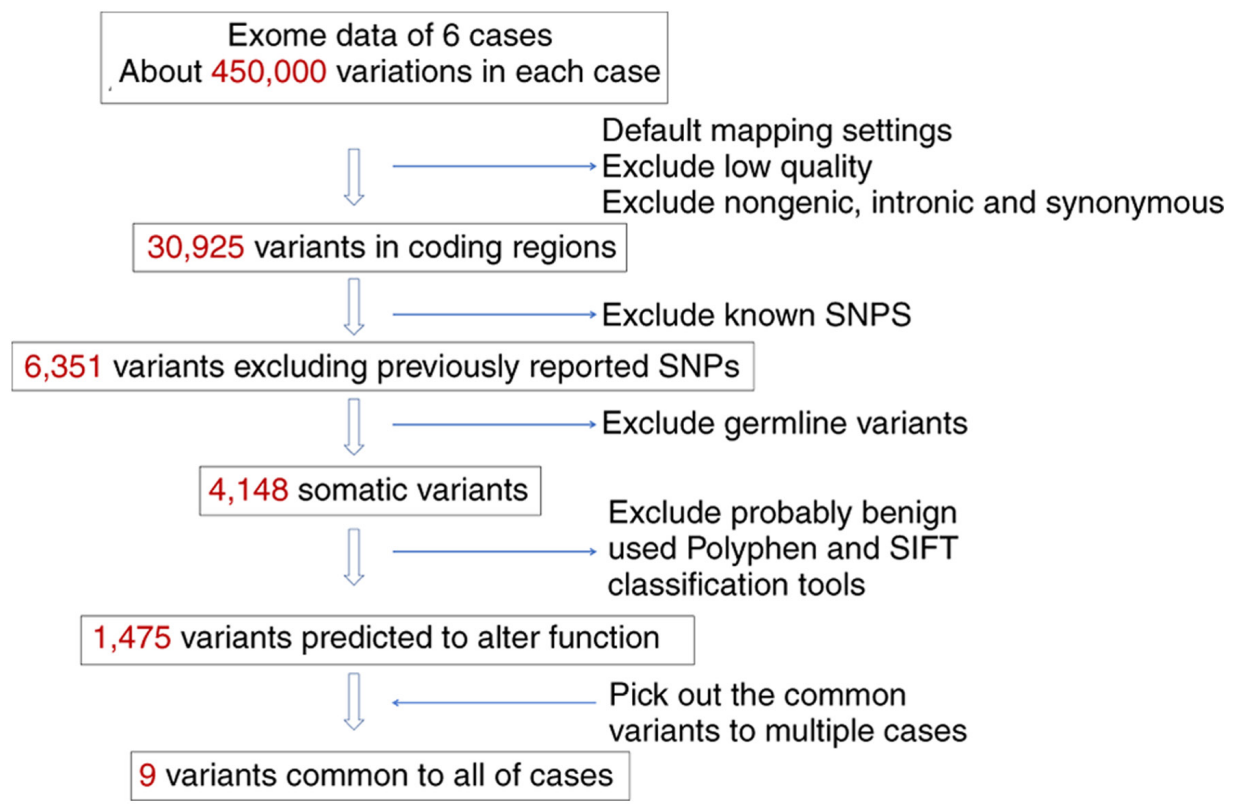

Figure 2. Schematic of bioinformatics single-nucleotide variant detection workflow. A total of 30,925 coding-region variants among 450,000 variations in each case were identified. Previously reported variants in the dbSNP database were excluded and germline variants were found in the matching blood samples, and variations likely to affect the respective protein functions using Pholyphen and SIFT tools were selected. Finally, variants common to multiple cases were selected.

used for univariate and multivariate analyses of prognostic factors (16). $\mathrm{P}<0.05$ was considered significant. The associations between mRNA and protein expression were assessed by Student's t-test. This study complied with the reporting recommendations for tumor marker prognostic studies (REMARK) criteria $(17,18)$.

\section{Results}

Identification of common relevant somatic mutations. Six patients whose tumors responded well to anthracycline treatment but showed rapid growth during NAC taxane treatment were analyzed in the present study (Table I). Computed tomography scans were performed to determine the tumor diameter and efficacy of each NAC regimen. The response criteria were the Response Evaluation Criteria in Solid Tumors (RECIST) criteria (version 1.1) (19). Details are shown in Table SI. WES of the tumor samples was also performed using Illumina
HiSeq to investigate the mechanisms responsible for taxane resistance, and in three available patient blood samples to exclude germline variants.

Approximately 450,000 genetic variations per individual were identified (Fig. 2). Low-quality mapping, and all non-genomic, intronic, and synonymous variants were excluded. Finally, 30,925 variants were identified in coding regions. The variants were further filtered by excluding all known variants through comparison with the dbSNP database v130, and 6,351 variants were selected. After excluding germline variants on the basis of exome data from the blood samples, 4,148 somatic variants were selected. Not all mutations are likely to be pathologically relevant, and thus those likely to affect protein function or those that affected highly conserved amino acids, making them functionally important, were selected. The functional consequences of amino acid changes using the Polyphen2, PROVEAN and SIFT classification tools were predicted, and 1,475 genes had at 

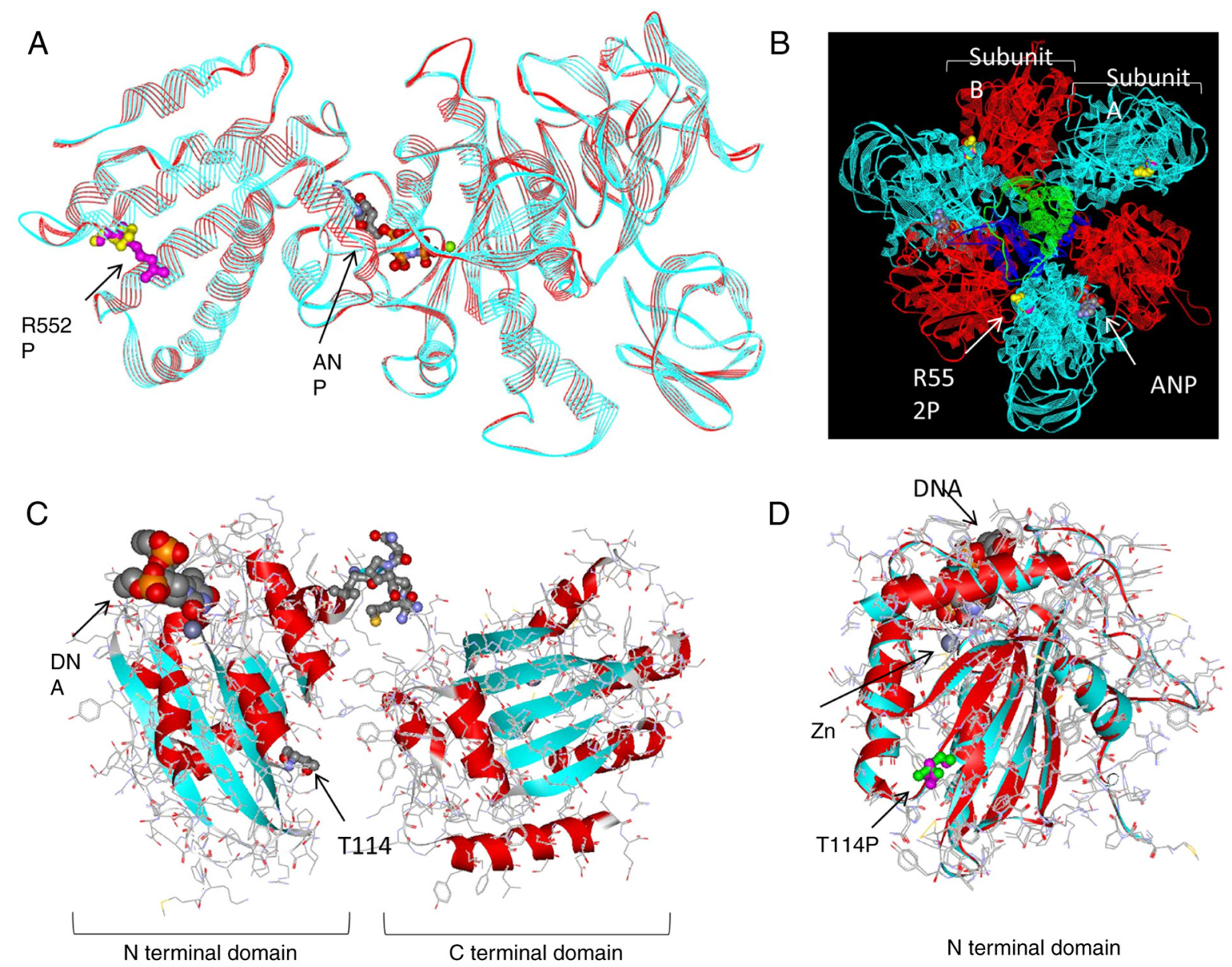

$\mathrm{N}$ terminal domain

Figure 3. Protein structure visualization of ATP6VIA and APOBEC3F somatic mutations. (A) Superimposed modeling of ATP6V1A. Turquoise ribbons, main wild-type chains; red ribbons, main mutant chains; magenta spheres, R552 (wild-type); yellow spheres, P552 (mutant-type). Gray and red balls in the center show ANP, an analog of ATP. (B) Octamer modeling of V-ATPase V1 domain. Turquoise ribbons: subunit A (encoded by ATP6V1A), red ribbons: subunit B, green ribbon: subunit D and blue ribbon: subunit F; magenta and yellow spheres: R552P; gray and red spheres: ANP. (C) Predicted model of wild-type APOBEC3F. Turquoise and red ribbons: main wild-type chains; small gray and red spheres in upper center: undetermined area; small gray and red spheres in lower center: T114 (wild-type); large gray, red, and orange spheres model: DNA. (D) Superimposed model of N-terminal domain of APOBEC3F. Turquoise ribbons: main wild-type chains; red ribbons: main mutant chains; green spheres: T114 (wild-type); magenta spheres: P114 (mutant-type). ANP, phospho-aminophosphonic acid-adenylate ester; ATP, adenosine triphosphate.

least one potentially destructive mutation. Subsequently, variants common to multiple cases were sought, and nine variants of eight different genes common to all six cases were identified.

Protein structure visualization of ATP6V1A and APOBEC3F somatic mutations. The nine variants were narrowed down to two variations on two different genes: the R552P mutation of ATP6V1A [variant allele frequency (VAF): 0.44] and the T114P mutation of APOBEC3F (VAF: 0.45). These variations were chosen by focusing on the role of the V-ATPase, the functional structure of ATP6V1A, in cancer metastasis (20), and because only T114P in APOBEC3F was predicted to damage the protein structure by all three online prediction tools utilized in the present study.

The structural changes caused by the R552P mutation of ATP6V1A are shown in Fig. 3A. ATP6V1A encodes subunit A of the $\mathrm{V} 1$ domain of the heteromultimeric vacuolar $\mathrm{H}^{+}$-ATPase (V-ATPase) complex. The V1 domain forms an $\mathrm{A}_{3} \mathrm{~B}_{3} \mathrm{DF}$ catalytic octamer with $\mathrm{B}, \mathrm{D}$, and $\mathrm{F}$ subunits. We considered that the ATP6V1A R552P mutation may cause structural changes because it was located at the border of subunit A (Fig. 3B). The pathological prediction score was calculated using two additional online prediction tools: the FATHMM score was 0.99 (pathogenic) and the Mutation Taster score was 103 (disease-causing).

APOBEC3F can deaminate DNA cytosine to uracil in a zinc-dependent manner. APOBEC3F has two zinc-binding sites: one in the $\mathrm{N}$-terminal domain and one in the $\mathrm{C}$-terminal domain (Fig. 3C). The results showed that the T114P mutation may also cause some structural changes because of its location near a zinc-binding site, which is the deaminase-active region (Fig. 3D). The T114P of APOBEC3F was predicted to damage the protein in three online prediction tools at the selection stage, but when calculated using two additional online prediction tools, the FATHMM score was 0.04 (neutral) and the Mutation Taster score was 38 (polymorphism).

No mutations were identified by Sanger sequencing. A search for R552P in ATP6V1A and T114P in APOBEC3F 
Table II. Clinicopathological characteristics of patients.

\begin{tabular}{|c|c|c|}
\hline Characteristics & $\begin{array}{c}\text { Samples for } \\
\text { mRNA } \\
\text { analysis }(\%)\end{array}$ & $\begin{array}{l}\text { Samples for } \\
\text { immunohisto- } \\
\text { chemistry (\%) }\end{array}$ \\
\hline No. of patients & 119 & 102 \\
\hline \multicolumn{3}{|l|}{ Age (years) } \\
\hline Mean \pm SD & $49.0 \pm 9.4$ & $48.8 \pm 8.9$ \\
\hline Range & $26-70$ & $26-75$ \\
\hline \multicolumn{3}{|l|}{ Histology } \\
\hline Invasive ductal carcinoma & $103(87)$ & $90(88)$ \\
\hline Invasive lobular carcinoma & $5(4)$ & $5(5)$ \\
\hline Ductal carcinoma in situ & $0(0)$ & $0(0)$ \\
\hline Other special types & $11(9)$ & $7(7)$ \\
\hline \multicolumn{3}{|l|}{ Tumor size } \\
\hline$\leq 2.0$ & $54(45)$ & $51(50)$ \\
\hline $2.1-5.0$ & $54(45)$ & $43(42)$ \\
\hline$>5.0$ & $8(7)$ & $7(7)$ \\
\hline Unknown & $3(3)$ & $1(1)$ \\
\hline \multicolumn{3}{|l|}{ No. of positive lymph nodes } \\
\hline 0 & $35(29)$ & $32(31)$ \\
\hline $1-3$ & $60(50)$ & $49(48)$ \\
\hline $4-9$ & $14(12)$ & $14(14)$ \\
\hline$\geq 10$ & $9(8)$ & $6(6)$ \\
\hline Unknown & $1(1)$ & $1(1)$ \\
\hline \multicolumn{3}{|l|}{ Nuclear grade } \\
\hline 1 & $33(28)$ & $29(28)$ \\
\hline 2 & $27(23)$ & $23(23)$ \\
\hline 3 & $55(46)$ & $49(48)$ \\
\hline Unknown & $4(3)$ & $1(1)$ \\
\hline \multicolumn{3}{|l|}{ ER (Allred score) } \\
\hline Positive (3-8) & $99(83)$ & $88(86)$ \\
\hline Negative (0-2) & $19(16)$ & $14(14)$ \\
\hline Unknown & $1(1)$ & $0(0)$ \\
\hline \multicolumn{3}{|l|}{ PgR (Allred score) } \\
\hline Positive (3-8) & $82(69)$ & $72(70)$ \\
\hline Negative (0-2) & $33(28)$ & $29(29)$ \\
\hline Unknown & $4(3)$ & $1(1)$ \\
\hline \multicolumn{3}{|l|}{ HER2 (Hercep test) } \\
\hline $0,1+$ & $92(77)$ & $81(80)$ \\
\hline $2+$ & $8(7)$ & $7(6)$ \\
\hline $3+$ & $16(13)$ & $13(12)$ \\
\hline Unknown & $4(3)$ & $2(2)$ \\
\hline \multicolumn{3}{|l|}{ Adjuvant therapy } \\
\hline Paclitaxel & $71(60)$ & $58(57)$ \\
\hline Docetaxel & $48(40)$ & $44(43)$ \\
\hline
\end{tabular}

ER, estrogen receptor; HER2, human epidermal growth factor receptor 2; PgR, progesterone receptor; SD, standard deviation.

in 119 breast cancers treated with taxanes was conducted. None of the mutations described above were found in Sanger sequencing.
mRNA expression analysis in breast cancer patients. The functions of ATP $6 V 1 A$ and $A P O B E C 3 F$ may be important and predicted that overexpression of $A T P 6 V 1 A$ or $A P O B E C 3 F$ may affect taxane resistance. Thus, the correlation between the mRNA expression levels of the two genes and patient prognosis in 119 breast cancers treated with taxanes at our institute was examined (Table II). The Kaplan-Meier analysis revealed that higher ATP6V1A expression was inversely correlated with DFS $(\mathrm{P}<0.0001)$ and $\mathrm{OS}(\mathrm{P}=0.002)$ (Fig. 4A and $\mathrm{B})$. Inverse correlations were also found between $A P O B E C 3 F$ expression and DFS $(\mathrm{P}=0.0005)$ and $\mathrm{OS}(\mathrm{P}=0.007)$ (Fig. $4 \mathrm{C}$ and $\mathrm{D})$.

The multivariate analysis revealed a high ATP6V1A mRNA expression as an independent prognostic factor for poor DFS (hazard ratio: 3.85 ; 95\% confidence interval: 1.43-9.89; $\mathrm{P}=0.009$; Table III). A ROC curve analysis was carried out to determine the cut-off values of ATP6VIA and APOBEC $3 F$ mRNA using Youden's index (sensitivity + specificity - 1). Cut-off levels for relative ATP6VIA and APOBEC $3 F$ mRNA expression were 3.5 and 2.1, respectively. ROC area under the curve (AUC) was 0.56 for DFS according to ATP6V1A mRNA expression, and the ROC AUC was 0.67 for DFS according to the $A P O B E C 3 F$ mRNA expression.

Protein expression of ATP6V1A and APOBEC3F in breast cancer. IHC was performed to analyze the protein expression levels in samples from 102 breast cancers treated with taxanes at our institute (Table II). Representative images of ATP6V1A and APOBEC3F protein expression are shown in Fig. 5. High and low expression of ATP6V1A (Fig. 5A and B) as well as high and low expression of APOBEC3F (Fig. 5C and D) are shown, respectively. The correlations between ATP6V1A and APOBEC3F protein expression levels and patient prognosis were then investigated. In the Kaplan-Meier analyses, high ATP6V1A or APOBEC3F protein expression showed a tendency to be associated with poor DFS. However, no significant difference was observed (Fig. 6A and C). In addition, the Kaplan-Meier analyses revealed no stratification of OS according to ATP6V1A or APOBEC3F protein expression levels (Fig. 6B and D). The cut-off levels for relative ATP6V1A and APOBEC3F H-score were 85.0 and 49.6, respectively, while the ROC AUC for DFS was 0.49 and 0.58 , respectively. As an AUC of 0.49 or 0.58 does not indicate good discriminatory power, the cut-off values for both mRNA levels should be re-evaluated using a different dataset in the future.

Next, the association between mRNA and protein expression was examined. There was no significant association between ATP6V1A mRNA and protein expression. However, a significant positive association was found between APOBEC3F mRNA and protein expression $(\mathrm{P}=0.01)$ (data not shown).

\section{Discussion}

In this study, we identified two different mutations in two genes that may affect taxane resistance in breast cancer patients using WES: R552P in ATP6VIA and T114P in APOBEC3F. Results of the present study suggested that these mutations caused structural changes in their respective proteins. Furthermore, high mRNA expression levels of these genes were correlated 
Table III. Univariate and multivariate analyses of factors predicting disease-free survival $(\mathrm{n}=119)$.

\begin{tabular}{|c|c|c|c|c|c|c|}
\hline \multirow[b]{2}{*}{ Variables } & \multicolumn{3}{|c|}{ Univariate } & \multicolumn{3}{|c|}{ Multivariate } \\
\hline & HR & $95 \% \mathrm{CI}$ & P-value & HR & $95 \% \mathrm{CI}$ & P-value \\
\hline Tumor size $(\mathrm{cm})$ & 1.11 & $0.91-1.30$ & 0.28 & & & \\
\hline Lymph nodes (Positive/Negative) & 1.05 & $0.51-2.31$ & 0.90 & & & \\
\hline Tumor grade & 1.60 & $1.03-2.59$ & $0.03^{\mathrm{a}}$ & 1.37 & $0.81-2.44$ & 0.24 \\
\hline ER (Positive/Negative) & 0.41 & $0.20-0.93$ & $0.03^{\mathrm{a}}$ & & & \\
\hline PgR (Positive/Negative) & 0.32 & $0.16-0.66$ & $0.002^{\mathrm{a}}$ & 0.32 & $0.14-0.75$ & $0.008^{\mathrm{a}}$ \\
\hline HER2 (Positive/Negative) & 1.49 & $0.63-3.16$ & 0.35 & & & \\
\hline ATP6V1A (High/Low) & 5.29 & $2.56-10.53$ & $<0.0001^{\mathrm{a}}$ & 3.85 & $1.43-9.89$ & $0.009^{\mathrm{a}}$ \\
\hline APOBEC3F (High/Low) & 3.23 & $1.58-6.48$ & $0.002^{\mathrm{a}}$ & 1.88 & $0.66-4.82$ & 0.21 \\
\hline
\end{tabular}

${ }^{\mathrm{a}} \mathrm{P}<0.05 . \mathrm{Cl}$, confidence interval; ER, estrogen receptor; HER2, human epidermal growth factor receptor 2; HR, hazard ratio; PgR, progesterone receptor.
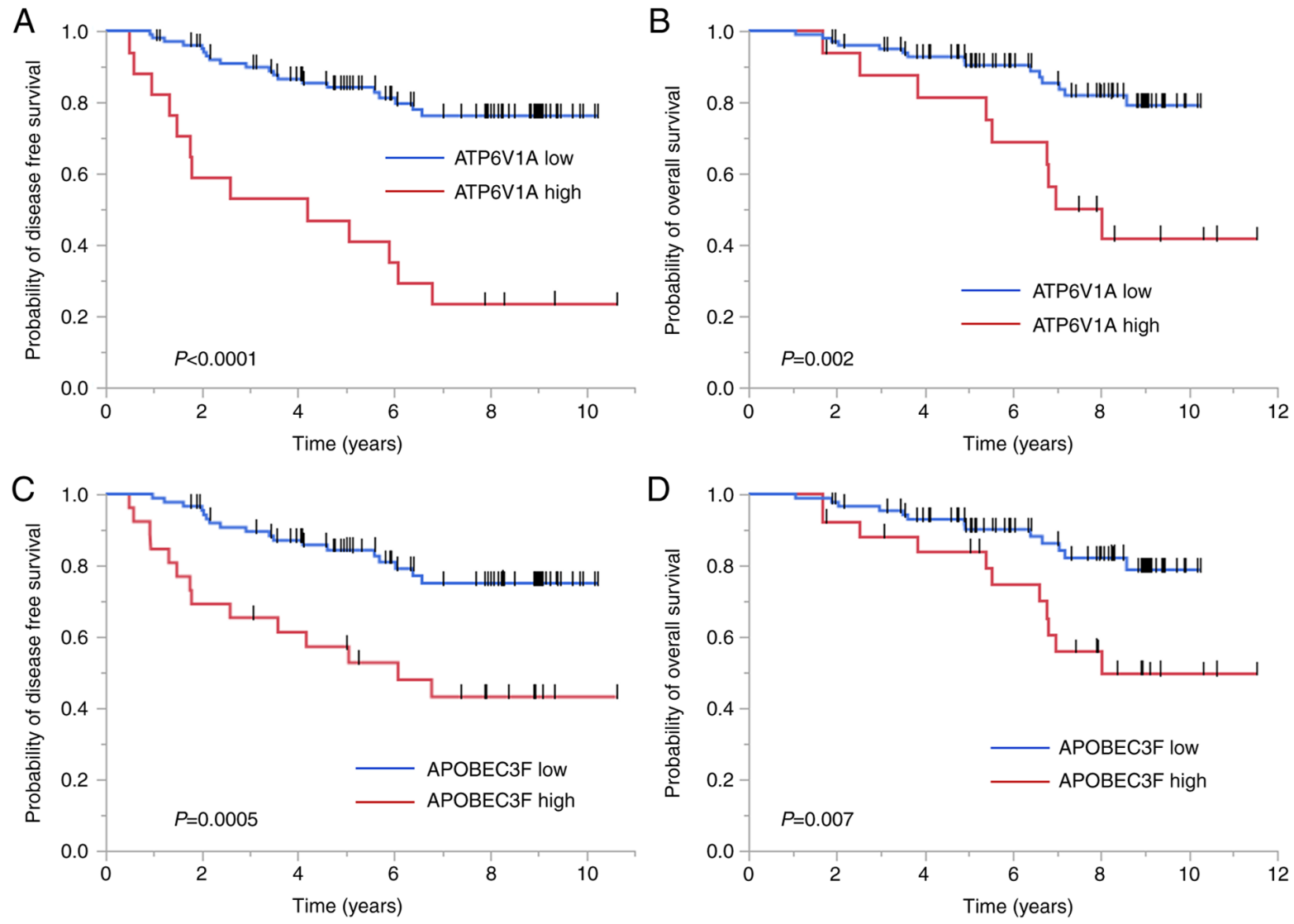

Figure 4. Kaplan-Meier survival analyses of 119 breast cancer patients who underwent taxane chemotherapy. (A) DFS and (B) OS stratified by expression levels of ATP6V1A mRNA. (C) DFS and (D) OS stratified by expression levels of APOBEC3F mRNA. DFS, disease-free survival; OS, overall survival.

with poor prognoses in breast cancer patients treated with taxanes.

ATP6V1A encodes subunit A of V-ATPase, which has a total of 14 different subunits arranged in two functional domains (21). V-ATPase is a proton pump that is present in intracellular and plasma membranes and regulates $\mathrm{pH}$ homeostasis in all eukaryotic cells $(22,23)$. A literature search revealed no reports of the $\mathrm{R} 552 \mathrm{P}$ mutation in ATP6V1A with respect to taxane resistance. The reason for this may be that the frequency of this mutation itself is rare. However, this mutation was common to all six patients in the current study, whose breast cancers grew rapidly during taxane-based NAC. This mutation may cause structural, and therefore functional, changes in the ATP6V1A protein, although the significance of this mutation remains unclear.

V-ATPase is present in many types of cancer cells (20) and its dysregulation has been reported to affect drug resistance through $\mathrm{pH}$ dysregulation of the cytoplasm and extracellular 

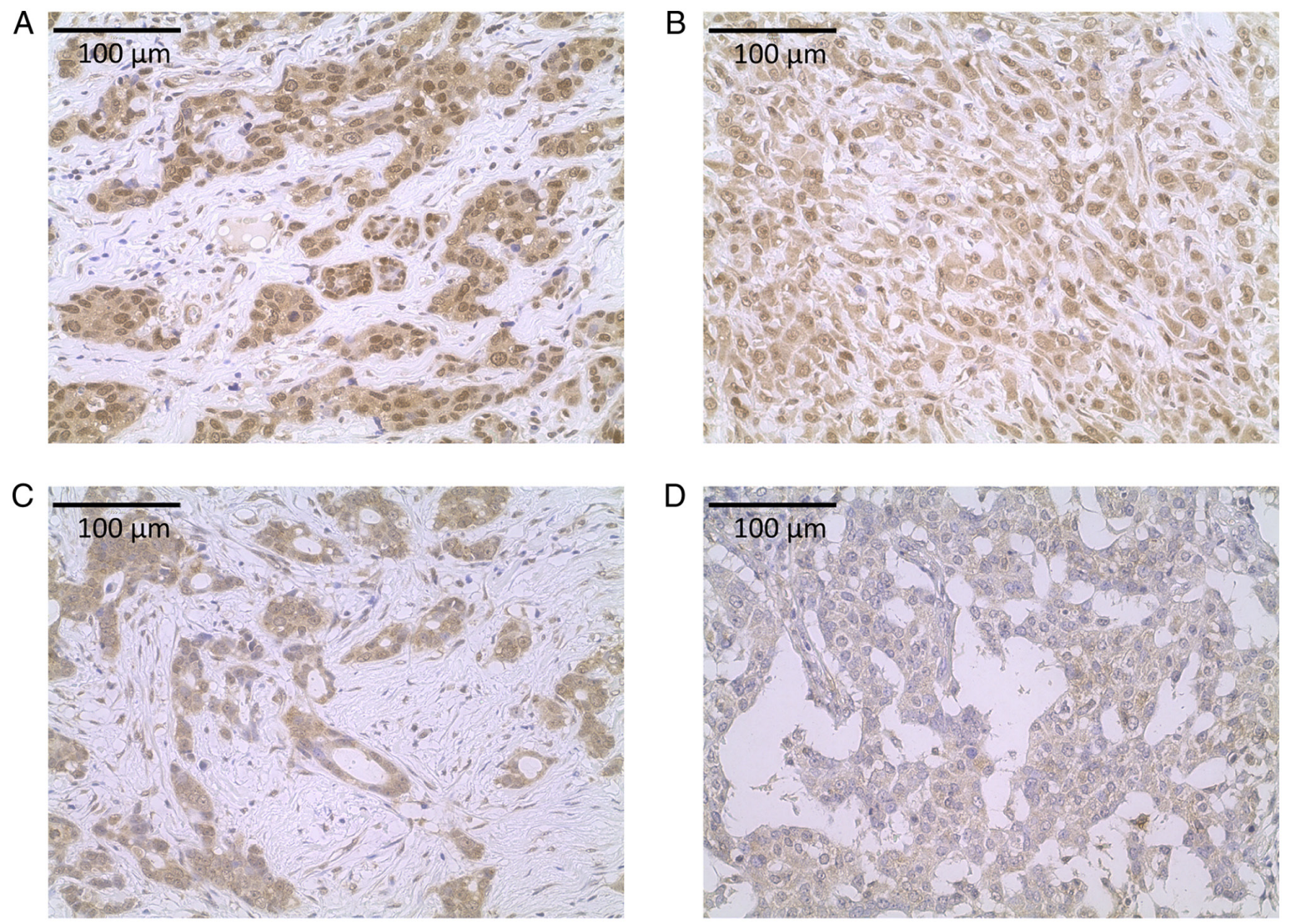

Figure 5. Representative images of ATP6V1A and APOBEC3F protein expression. (A) H-score 160 and high ATP6V1A expression. (B) H-score 45 and low ATP6V1A expression. (C) H-score 104 and high APOBEC3F expression. (D) $\mathrm{H}$-score 4 and low APOBEC3F expression.
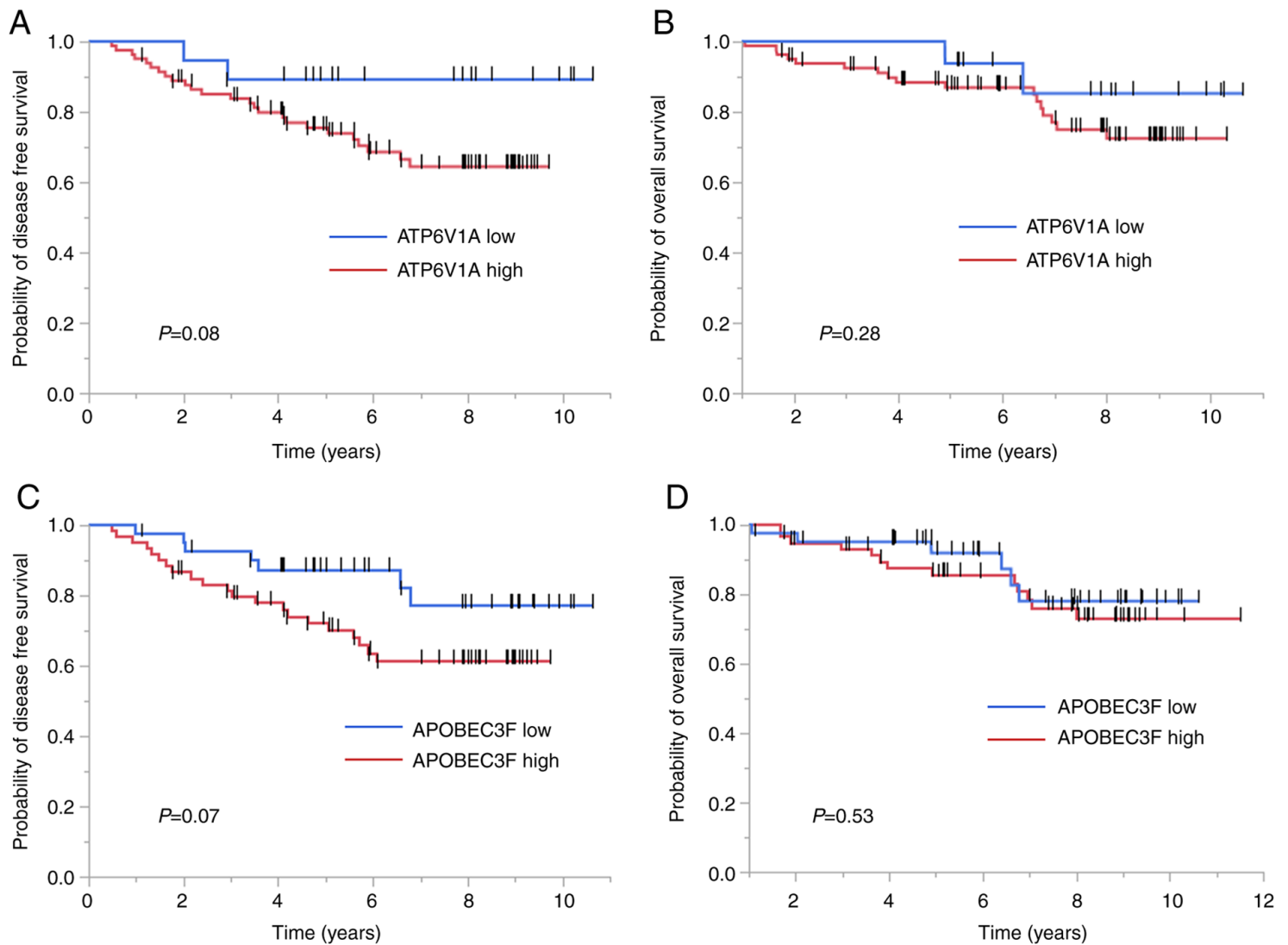

Figure 6. Kaplan-Meier survival analyses of 102 breast cancer patients who received taxane chemotherapy. (A) DFS and (B) OS stratified by expression levels of ATP6V1A protein. (C) DFS and (D) OS stratified by expression levels of APOBEC3F protein. DFS, disease-free survival; OS, overall survival. 


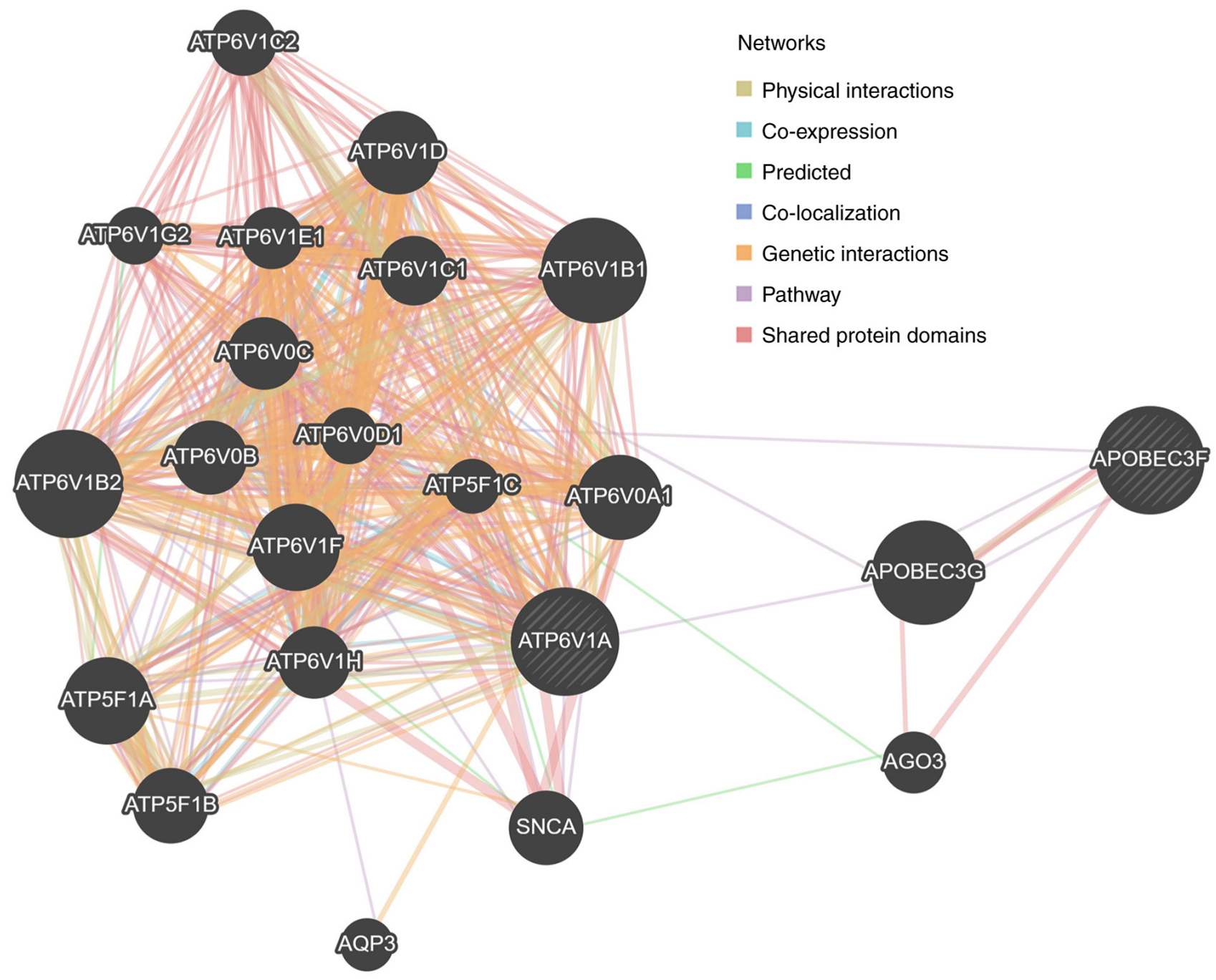

Figure 7. Interaction between ATP6V1A and APOBEC3F. Interaction analysis identified 17 genes involved in V-ATPase and five genes involved with the APOBEC3 family. ATP6V1A was predicted to be co-expressed with APOBEC3F via APOBEC3G.

environment $(22,24)$. V-ATPase hyperactivity has been demonstrated to induce drug resistance, whereas V-ATPase inhibition could overcome drug resistance $(25,26)$. Another study reported that a lower extracellular $\mathrm{pH}$ increased the migratory capacity and resistance of MCF7 cells to docetaxel and paclitaxel (27). Abnormalities in V-ATPase may thus cause $\mathrm{pH}$ dysregulation, leading to taxane resistance. In the present study, we identified a novel mutation, R552P in ATP6V1A, which was common to all intrinsically taxane-resistant cases in our cohort following NGS. The R552P mutation in ATP6V1A was determined to be a pathogenic mutation by four online prediction tools. This mutation introduces a proline into the alpha-helix. Out of 20 essential amino acids, proline is the only amino acid that contains a cyclized substituted $\alpha$-amino group (is formally an imino acid) and has an important role in the protein folding process because of its structural properties $(28,29)$. Proline is recognized as a helix-breaking amino acid, and it has been reported that replacement of residues in the alpha-helix with proline can destabilize the protein structure (29). Thus, the R552P mutation in ATP6V1A may cause structural changes in ATP6V1A protein. A high ATP6V1A mRNA expression was also significantly associated with a poorer prognosis in patients who received taxane treatment for breast cancer. These results suggest that structural changes and the overexpression of ATP6V1A may cause V-ATPase hyperactivity and taxane resistance in breast cancer. However, previous evidence suggested that changes in cytosolic $\mathrm{pH}$ resulting from a higher activity of V-ATPase and the proton transporters can affect the packing of lipids and decrease the movement of doxorubicin, an anthracycline $(30,31)$. The present analysis is based on cases in which taxane anticancer drugs were used. Since anthracyclines are also used in many cases, their influence cannot be ignored.

Dysregulation of the V-ATPase subunit was also linked to poor cancer outcome (24). Liu et al (32) reported that ATP6V1A protein expression levels were higher in gastric cancer compared with normal tissues and were correlated with worse survival. V-ATPase and its subunits have been reported to be more highly expressed in many types of cancer tissues, including breast cancer, compared with normal tissues, and its high expression was also reportedly associated with a poor prognosis $(24,33,34)$. In the current study, high ATP6VIA mRNA expression was significantly associated with a poor prognosis and was an independent predictor of poor prognosis 
in breast cancer patients receiving taxane treatment. Although, to the best of our knowledge, the current study was the first to report the correlation between mRNA expression levels of ATP6V1A in breast cancer and patient outcomes, a high expression of the V-ATPase subunit component gene was also identified as a poor prognostic factor in previous studies (24), suggesting that a high ATP6V1A mRNA expression and increased ATP6V1A function may be associated with a poor prognosis in breast cancer.

$A P O B E C 3 F$ is a member of the cytidine deaminase gene family, which encodes proteins that are structurally and functionally related to $\mathrm{C}$ to U RNA editing (35). However, the correlation between $A P O B E C 3 F$ somatic mutations and cancer has not been widely investigated. In the current study, we identified the T114P mutation as a novel $A P O B E C 3 F$ gene variant by NGS. The T114P mutation of APOBEC3F was predicted to be a pathogenic mutation by three of five online prediction tools. This mutation also produced a change to proline but was not located inside the alpha-helix. Although its significance is unclear, this mutation was common to all intrinsically taxane-resistant cases in the current study and was predicted to cause structural changes in the APOBEC $3 \mathrm{~F}$ protein.

DNA de-amination activity of APOBEC3 family proteins has been identified as a major contributor to mutagenesis in various types of cancer, including breast cancer $(36,37)$. APOBEC3B, another APOBEC3 family member, is involved in genetic changes in breast cancer (38), and $A P O B E C 3 B$ mRNA expression was associated with poorer survival in ER-positive breast cancer $(39,40)$. However, the role of APOBEC3F in breast cancer has not been widely studied. APOBEC3F is endogenously expressed in human $\mathrm{T}$ cells, where it mediates antiviral immunity by catalyzing mutations in the viral genome $(36,37)$. Yang et al $(41,42)$ demonstrated that the overexpression of APOBEC3F was a risk factor for poor survival and tumor aggressiveness in hepatocellular carcinoma (HCC). In the current study, a higher APOBEC3F expression was associated with poor breast cancer prognosis. Although the study by Yang et al (42) involved different cancer types, their findings regarding APOBEC 3F were similar to those of the present study. Given that the overexpression of APOBEC3F reduced the immune function against breast cancer, as in $\mathrm{HCC}$, APOBEC3F is a potential therapeutic target in these forms of cancer.

The interaction between ATP6V1A and APOBEC3F is shown in Fig. 7 (created by GeneMANIA), based on previous reports (43). According to this analysis, ATP6V1A is predicted to be co-expressed with APOBEC3F via APOBEC3G.

However, no other tumors with the same mutations were identified. Mutations common to taxane-resistant tumors are rare. However, the current six cases with mutations identified by NGS were not clearly identified by Sanger sequencing, suggesting that the detection rate of Sanger sequencing should be reviewed.

The present study had some limitations. The prognosis evaluations were based on retrospective analyses of archived materials from a single institute. In addition, we examined only cases in which taxanes were used and did not include a control group. For this reason, patients with a good prognosis who could avoid anti-cancer drugs were not included.
Although we used this group of patients for an exploratory study, there is a possibility of bias due to this factor. As shown in Table SII, a comparison of the clinicopathological factors of all patients who were treated for breast cancer at the same time and in those who had their mRNA expression measured revealed significant differences in histology, number of lymph node metastases, nuclear grade, and HER2 expression. A high ATP6V1A and APOBEC3F protein expression showed a tendency to be associated with poor prognosis. However, no significant difference was observed. There are three possible reasons for the lack of significant differences in the correlation between prognosis and protein expression. First, the number of cases was insufficient. Second, the IHC methodology for ATP6V1A and APOBEC3F protein evaluation has not been well established. Third, because long-term follow-up tissues were used in this study, the rate of positive staining may have changed because of tissue deterioration over time.

This study attempted to identify novel mutations associated with taxane resistance. ATP6V1A is a therapeutic target, and drugs targeting ATP6V1A and inhibiting V-ATPase-dependent growth signaling have been reported (44). An APOBEC3F-targeting drug that inhibits cell proliferation and migration has also been reported for the treatment of HCC (41). Future research is to focus on investigating the mechanism of ATP6V1A and APOBEC3F against taxane resistance in in vitro studies and analyzing the specific function of each gene in addition to taxane resistance.

Although attempts at cell culture studies are currently underway, it remains difficult to include the data owing to the restrictions resulting from the COVID-19 pandemic regarding the use of cell laboratories.

In conclusion, using NGS, we identified two specific mutations, R552P in ATP6V1A and T114P in APOBEC3F, which were common to all intrinsically taxane-resistant breast cancer patients in this study. The two mutations appeared to change their respective protein structures. The results also showed that, among patients who receive taxane treatment for breast cancer, those with high ATP6V1A or APOBEC $3 F$ expression levels are likely to have shorter survival.

\section{Acknowledgements}

The authors would like to thank Mrs. Shinobu Makino (Department of Breast Surgery, Nagoya City University Graduate School of Medical Sciences, Nagoya, Japan) for her technical assistance. The authors would also like to thank Dr Marla Brunker, Dr Susan Furness and Dr H. Nikki March for editing drafts of this manuscript.

\section{Funding}

This work was supported by a Grant-in-Aid for Scientific Research from the Ministry of Education, Culture, Sports, Science, and Technology of Japan (MEXT) KAKENHI (grant no. 19K09080).

\section{Availability of data and materials}

The datasets generated and/or analyzed during the current study are available from the Japanese Genotype-Phenotype 
Archive (JGA) database repository on reasonable request. The accession numbers are Study: JGAS000370, Dataset: JGAD000484. (https://www.ddbj.nig.ac.jp/jga/index-e.html).

\section{Authors' contributions}

YWE conceived and designed the study and evaluated the results. YWE and YD conducted $\mathrm{mRNA}$ expression and immunostaining analyses. TF, TA, TH, YU, SN, YK, AK, MT and HS provided tissue samples and assessed patient data. $\mathrm{KO}, \mathrm{HK}$ and ST assisted in evaluation of the results. NK and TT contributed to theoretical organization of the study, the research design, and revising and editing of the manuscript and confirmed the authenticity of all the raw data. All authors read and approved the final manuscript.

\section{Ethics approval and consent to participate}

This study was approved by the Institutional Review Board of Nagoya City University (approval no. 70-00-0172; Nagoya, Japan). All tissue samples were provided by a biobank maintained by the Department of Breast Surgery, Nagoya City University, which conforms to the guidelines of the Declaration of Helsinki. Written informed consent for the comprehensive research use of clinical samples was obtained from all 1,707 patients involved in this study.

\section{Patient consent for publication}

Not applicable.

\section{Competing interests}

The authors declare that they have no competing interests.

\section{References}

1. Mougalian SS, Soulos PR, Killelea BK, Lannin DR, Abu-Khalaf MM, DiGiovanna MP, Sanft TB, Pusztai L, Gross CP and Chagpar AB: Use of neoadjuvant chemotherapy for patients with stage I to III breast cancer in the United States. Cancer 121: 2544-2552, 2015.

2. Bear HD, Anderson S, Brown A, Smith R, Mamounas EP, Fisher B, Margolese R, Theoret H, Soran A, Wickerham DL, et al: The effect on tumor response of adding sequential preoperative docetaxel to preoperative doxorubicin and cyclophosphamide: Preliminary results from national surgical adjuvant breast and bowel project protocol B-27. J Clin Oncol 21: 4165-4174, 2003.

3. Caudle AS, Gonzalez-Angulo AM, Hunt KK, Liu P, Pusztai L, Symmans WF, Kuerer HM, Mittendorf EA, Hortobagyi GN and Meric-Bernstam F: Predictors of tumor progression during neoadjuvant chemotherapy in breast cancer. J Clin Oncol 28: $1821-1828,2010$.

4. Pucci P, Rescigno P, Sumanasuriya S, de Bono J and Crea F: Hypoxia and noncoding RNAs in taxane resistance. Trends Pharmacol Sci 39: 695-709, 2018.

5. Yin S, Zeng C, Hari M and Cabral F: Paclitaxel resistance by random mutagenesis of alpha-tubulin. Cytoskeleton (Hoboken) 70: 849-862, 2013.

6. Matsunaga T, Saito H, Endo S, Iguchi K, Soda M, El-Kabbani O, Hara A and Ikari A: Roles of aldo-keto reductases 1B10 and 1C3 and ATP-binding cassette transporter in docetaxel tolerance. Free Radic Res 50: 1296-1308, 2016.

7. Vaidyanathan A, Sawers L, Gannon AL, Chakravarty P, Scott AL, Bray SE, Ferguson MJ and Smith G: ABCB1 (MDR1) induction defines a common resistance mechanism in paclitaxel- and olaparib-resistant ovarian cancer cells. Br J Cancer 115: 431-441, 2016.
8. Bose R, Kavuri SM, Searleman AC, Shen W, Shen D, Koboldt DC, Monsey J, Goel N, Aronson AB, Li S, et al: Activating HER2 mutations in HER2 gene amplification negative breast cancer. Cancer Discov 3: 224-237, 2013

9. Yang L, Ye F, Bao L, Zhou X, Wang Z, Hu P, Ouyang N, Li X, Shi Y, Chen G, et al: Somatic alterations of TP53, ERBB2, PIK3CA and CCND1 are associated with chemosensitivity for breast cancers. Cancer Sci 110: 1389-1400, 2019.

10. Endo Y, Dong Y, Yoshimoto N, Asano T, Hato Y, Yamashita H, Sato S, Takahashi S, Fujii Y and Toyama T: HER2 mutation status in Japanese HER2-negative breast cancer patients. Jpn J Clin Oncol 44: 619-623, 2014.

11. Wanifuchi-Endo Y, Asano T, Kondo N, Hato Y, Dong Y, Hisada T, Nishikawa S, Kato H, Takahashi S, Okuda K, et al: Effects of serum estradiol and progesterone on estrogen-regulated gene expression in breast cancers of premenopausal patients. Jpn $\mathrm{J}$ Clin Oncol 49: 12-21, 2019.

12. Allred DC, Harvey JM, Berardo M and Clark GM: Prognostic and predictive factors in breast cancer by immunohistochemical analysis. Mod Pathol 11: 155-168, 1998.

13. Wolff AC, Hammond ME, Schwartz JN, Hagerty KL, Allred DC, Cote RJ, Dowsett M, Fitzgibbons PL, Hanna WM, Langer A, et al: American society of clinical oncology/college of american pathologists guideline recommendations for human epidermal growth factor receptor 2 testing in breast cancer. J Clin Oncol 25: 118-145, 2007.

14. Hirsch FR, Varella-Garcia M, Bunn PA Jr, Maria MV, Veve R, Bremmes RM, Barón AE, Zeng C and Franklin WA: Epidermal growth factor receptor in non-small-cell lung carcinomas: Correlation between gene copy number and protein expression and impact on prognosis. J Clin Oncol 21: 3798-3807, 2003.

15. John T, Liu G and Tsao MS: Overview of molecular testing in non-small-cell lung cancer: Mutational analysis, gene copy number, protein expression and other biomarkers of EGFR for the prediction of response to tyrosine kinase inhibitors. Oncogene 28 (Suppl 1): S14-S23, 2009.

16. Endo Y, Yamashita H, Takahashi S, Sato S, Yoshimoto N, Asano $T$, Hato $Y$, Dong $Y$, Fujii $Y$ and Toyama T: Immunohistochemical determination of the miR-1290 target arylamine N-acetyltransferase 1 (NAT1) as a prognostic biomarker in breast cancer. BMC Cancer 14: 990, 2014.

17. Hayes DF, Ethier S and Lippman ME: New guidelines for reporting of tumor marker studies in breast cancer research and treatment: REMARK. Breast Cancer Res Treat 100: 237-238, 2006.

18. McShane LM, Altman DG, Sauerbrei W, Taube SE, Gion M and Clark GM; Statistics Subcommittee of the NCI-EORTC Working Group on Cancer Diagnostics: REporting recommendations for tumor MARKer prognostic studies (REMARK). Breast Cancer Res Treat 100: 229-235, 2006.

19. Eisenhauer EA, Therasse P, Bogaerts J, Schwartz LH, Sargent D, Ford R, Dancey J, Arbuck S, Gwyther S, Mooney M, et al: New response evaluation criteria in solid tumours: Revised RECIST guideline (version 1.1). Eur J Cancer 45: 228-247, 2009.

20. Fais S, De Milito A, You H and Qin W: Targeting vacuolar $\mathrm{H}^{+}$-ATPases as a new strategy against cancer. Cancer Res 67: 10627-10630, 2007.

21. Nishi T and Forgac M: The vacuolar $\left(\mathrm{H}^{+}\right)$-ATPases-nature's most versatile proton pumps. Nat Rev Mol Cell Biol 3: 94-103, 2002.

22. Stransky L, Cotter K and Forgac M: The function of V-ATPases in cancer. Physiol Rev 96: 1071-1091, 2016.

23. Sun-Wada GH and Wada Y: Role of vacuolar-type proton ATPase in signal transduction. Biochim Biophys Acta 1847: 1166-1172, 2015.

24. Whitton B, Okamoto H, Packham G and Crabb SJ: Vacuolar ATPase as a potential therapeutic target and mediator of treatment resistance in cancer. Cancer Med 7: 3800-3811, 2018.

25. Sasazawa Y, Futamura Y, Tashiro E and Imoto M: Vacuolar $\mathrm{H}^{+}$-ATPase inhibitors overcome Bcl-xL-mediated chemoresistance through restoration of a caspase-independent apoptotic pathway. Cancer Sci 100: 1460-1467, 2009.

26. von Schwarzenberg K, Lajtos T, Simon L, Müller R, Vereb G and Vollmar AM: V-ATPase inhibition overcomes trastuzumab resistance in breast cancer. Mol Oncol 8: 9-19, 2014.

27. Tavares-Valente D, Baltazar F, Moreira R and Queirós O: Cancer cell bioenergetics and $\mathrm{pH}$ regulation influence breast cancer cell resistance to paclitaxel and doxorubicin. J Bioenerg Biomembr 45: 467-475, 2013.

28. Pakula AA and Sauer RT: Genetic analysis of protein stability and function. Annu Rev Genet 23: 289-310, 1989. 
29. MacArthur MW and Thornton JM: Influence of proline residues on protein conformation. J Mol Biol 218: 397-412, 1991.

30. Muley H, Fadó R, Rodriguez-Rodríguez R and Casals N: Drug uptake-based chemoresistance in breast cancer treatment. Biochem Pharmacol 177: 113959, 2020.

31. Fan S, Niu Y, Tan N, Wu Z, Wang Y, You H, Ke R, Song J, Shen Q, Wang W, et al: LASS2 enhances chemosensitivity of breast cancer by counteracting acidic tumor microenvironment through inhibiting activity of V-ATPase proton pump. Oncogene 32 : $1682-1690,2013$.

32. Liu P, Chen H, Han L, Zou X and Shen W: Expression and role of V1A subunit of V-ATPases in gastric cancer cells. Int J Clin Oncol 20: 725-735, 2015

33. Cotter K, Liberman R, Sun-Wada G, Wada Y, Sgroi D, Naber S, Brown D, Breton $\mathrm{S}$ and Forgac M: The a3 isoform of subunit a of the vacuolar ATPase localizes to the plasma membrane of invasive breast tumor cells and is overexpressed in human breast cancer. Oncotarget 7: 46142-46157, 2016.

34. Katara GK, Jaiswal MK, Kulshrestha A, Kolli B, Gilman-Sachs A and Beaman KD: Tumor-associated vacuolar ATPase subunit promotes tumorigenic characteristics in macrophages. Oncogene 33: 5649-5654, 2014.

35. Jarmuz A, Chester A, Bayliss J, Gisbourne J, Dunham I, Scott J and Navaratnam N: An anthropoid-specific locus of orphan C to U RNA-editing enzymes on chromosome 22. Genomics 79: 285-296, 2002.

36. Burns MB, Temiz NA and Harris RS: Evidence for APOBEC3B mutagenesis in multiple human cancers. Nat Genet 45: 977-983, 2013.

37. Roberts SA, Lawrence MS, Klimczak LJ, Grimm SA, Fargo D, Stojanov P, Kiezun A, Kryukov GV, Carter SL, Saksena G, et al: An APOBEC cytidine deaminase mutagenesis pattern is widespread in human cancers. Nat Genet 45: 970-976, 2013.

38. Burns MB, Lackey L, Carpenter MA, Rathore A, Land AM, Leonard B, Refsland EW, Kotandeniya D, Tretyakova N, Nikas JB, et al: APOBEC3B is an enzymatic source of mutation in breast cancer. Nature 494: 366-370, 2013.
39. Sieuwerts AM, Schrijver WA, Dalm SU, de Weerd V, Moelans CB, Hoeve NT, van Diest PJ, Martens JWM and van Deurzen CH: Progressive APOBEC3B mRNA expression in distant breast cancer metastases. PLoS One 12: e0171343, 2017.

40. Sieuwerts AM, Willis S, Burns MB, Look MP, Gelder ME, Schlicker A, Heideman MR, Jacobs H, Wessels L, Leyland-Jones B, et al: Elevated APOBEC3B correlates with poor outcomes for estrogen-receptor-positive breast cancers. Horm Cancer 5: 405-413, 2014.

41. Yang Z, Tao Y, Xu X, Cai F, Yu Y and Ma L: Bufalin inhibits cell proliferation and migration of hepatocellular carcinoma cells via APOBEC3F induced intestinal immune network for IgA production signaling pathway. Biochem Biophys Res Commun 503: 2124-2131, 2018

42. Yang Z, Zhuang L, Yu Y, Zhou W, Lu Y, Xu Q, Tang B and Chen X: Overexpression of APOBEC3F in tumor tissues is potentially predictive for poor recurrence-free survival from HBV-related hepatocellular carcinoma. Discov Med 20: 349-356, 2015.

43. Warde-Farley D, Donaldson SL, Comes O, Zuberi K, Badrawi R, Chao P, Franz M, Grouios C, Kazi F, Lopes CT, et al: The GeneMANIA prediction server: Biological network integration for gene prioritization and predicting gene function. Nucleic Acids Res 38: W214-W220, 2010.

44. Chung CY, Shin HR, Berdan CA, Ford B, Ward CC, Olzmann JA, Zoncu R and Nomura DK: Covalent targeting of the vacuolar $\mathrm{H}(+)$-ATPase activates autophagy via mTORC1 inhibition. Nat Chem Biol 15: 776-785, 2019.

This work is licensed under a Creative Commons Attribution-NonCommercial-NoDerivatives 4.0 International (CC BY-NC-ND 4.0) License. 